\title{
CURRENT-MODE UNIVERSAL FILTER USING FTFNs
}

\author{
MUHAMMAD TAHER ABUELMA'ATTI \\ and HUSAIN ABDULLAH AL-ZAHER \\ King Fahd University of Petroleum and Minerals, Box 203, Dhahran 31261, Saudi \\ Arabia
}

(Received 19 November, 1996; In final form 3 January, 1997)

\begin{abstract}
A new current-mode universal filter is presented. The proposed filter uses three four-terminal floating nullors (FTFNs), three grounded capacitors, and four grounded resistors. The proposed filter has three inputs and one output and can realize lowpass, highpass, bandpass, notch, and allpass transfer functions without changing the circuit topology. The proposed filter enjoys low active and passive sensitivities and independent control of the parameters $\omega_{0}$ and $\frac{\omega_{0}}{Q_{0}}$ using grounded elements.
\end{abstract}

\section{INTRODUCTION}

The four-terminal floating nullor (FTFN) is a more flexible and versatile building block than the operational amplifier and the current-conveyor [13]. This explains the growing interest in using the FTFN in designing current-amplifiers, voltage-to-current converters, gyrators, floating immittances [1,4-6], and more recently in designing current-mode active-RC filters [3,7-10] and sinusoidal oscillators [11,12]. In [3], a procedure is described for transforming voltage-mode circuits with operational amplifiers to current-mode circuits with FTFNs. Using this procedure, a current-mode lowpass transfer function is obtained from a Sallen-Key voltage-mode lowpass circuit. In [7], a stable grounded-capacitor, first-order allpass filter using an FTFN is presented. In [8], a cascadable current-mode configuration using single FTFN is presented. This configuration can realize second-order lowpass, highpass, bandpass, notch, and 
allpass filters. However, its active sensitivities are large and it requires a floating capacitor. Moreover, these five filters cannot be realized without changing the circuit topology to achieve a specific filter function. In [9], a current-mode configuration using two FTFNs is presented. This configuration enjoys low active and passive sensitivities and can simultaneously realize lowpas/bandpass, or highpass/bandpass or bandpass/notch filters using two grounded capacitors. It can also realize an allpass filter. However, it requires a floating resistor and more importantly, its parameters $\omega_{0}$ and $\omega_{0} / Q_{0}$ are interdependent. Thus, it is impossible to adjust any of these two parameters without disturbing the other parameter. In [10], a cascadable current-mode configuration using single FTFN enjoying low active and passive sensitivities is presented. This configuration can realize second-order lowpass, highpass, bandpass, allpass, and notch filters using six passive elements at most. These five filters, however, cannot be realized without changing the circuit topology to achieve a specific filter function.

Moreover, the parameters $\omega_{0}$ and $\frac{\omega_{0}}{Q_{0}}$ are interdependent.

We present a new current-mode biquad filter structure using three FTFNs, three grounded capacitors and four grounded resistors. The circuit can realize second-order lowpass, highpass, bandpass, allpass, and notch filters without changing its topology. The proposed circuit enjoys the attractive features of low active and passive sensitivities and the independent control of the parameters $\omega_{0}$ and $\omega_{0} / Q_{0}$ using grounded elements.

\section{PROPOSED CIRCUIT}

The proposed circuit is shown in Fig. 1. Assuming that the port relations of the FTFN, shown in Fig. 2, can be expressed as $I_{1}=I_{2}=0, V_{2}=\beta V_{1}$ and $I_{02}=\alpha I_{01}$ where $\beta=1-\varepsilon,(|\varepsilon| \ll 1)$, denote the voltage tracking error of the FTFN and $\alpha=1-\delta,(|\delta| \ll 1)$, denotes the current-tracking error, routine analysis of the circuit shown in Fig. 1 yields the current-transfer function expressed by

$$
I_{0}=\frac{s^{2} C_{2} C_{4} G_{6} I_{i n 3}-s \frac{\beta_{3}}{\alpha_{3}} C_{2} G_{5} G_{6} I_{i n 2}+\frac{\beta_{2} \beta_{3}}{\alpha_{1} \alpha_{2} \alpha_{3}} G_{3} G_{5} G_{6} I_{i n 1}}{s^{2} C_{2} C_{4} G_{6}+s \frac{\beta_{1} \beta_{2} \beta_{3}}{\alpha_{1} \alpha_{2} \alpha_{3}} C_{1} G_{3} G_{5}+\frac{\beta_{1} \beta_{2} \beta_{3}}{\alpha_{1} \alpha_{2} \alpha_{3}} G_{1} G_{3} G_{5}}
$$

where $\beta_{i}, \alpha_{i}, i=1-3$, are the voltage- and current-tracking errors of the ith FTFN. 


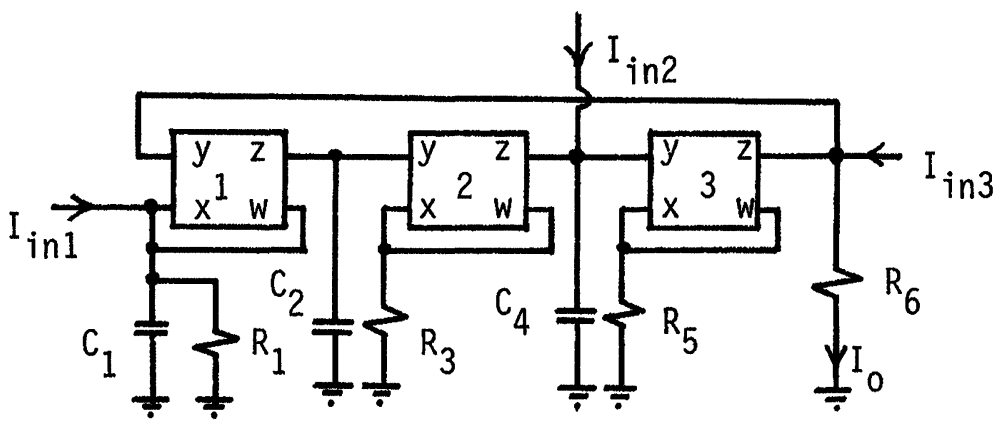

FIGURE 1 Proposed multiple-input Single-output current-mode Universal filter

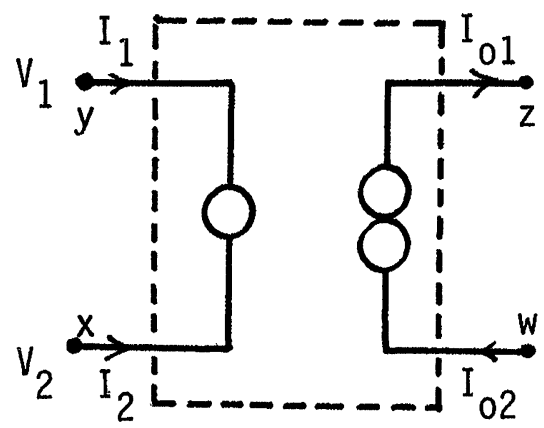

FIGURE 2 Nullor model of the FTFN

From (1) the parameters $\omega_{0}$ and $\frac{\omega_{0}}{Q_{0}}$ can be expressed as

and

$$
\omega_{0}^{2}=\frac{\beta_{1} \beta_{2} \beta_{3}}{\alpha_{1} \alpha_{2} \alpha_{3}} \frac{G_{1} G_{3} G_{5}}{C_{2} C_{4} G_{6}}
$$

$$
\frac{\omega_{0}}{Q_{0}}=\frac{\beta_{1} \beta_{2} \beta_{3}}{\alpha_{1} \alpha_{2} \alpha_{3}} \frac{C_{1} G_{3} G_{5}}{C_{2} C_{4} G_{6}}
$$

From (1), it can be seen that:

i. the lowpass response can be realized with $I_{i n 2}=I_{i n 3}=0$,

ii. the highpass response can be realized with $I_{\text {in } 1}=I_{\text {in } 2}=0$,

iii. the bandpass response can be realized with $I_{i n 1}=I_{i n 3}=0$

iv. the notch response can be realized with $I_{\text {in } 2}=0$, and $I_{\text {in } 1}=I_{\text {in } 3}$

v. the allpass response can be realized with

$$
I_{\text {in } 1}=I_{\text {in2 }}=I_{\text {in } 3} \text { and } G_{1}=G_{3}=G_{6}, C_{1}=C_{2} \text {. }
$$


From (1), it can be seen that the lowpass gain, the highpass gain and the bandpass gain are approximately given by

and

$$
\begin{aligned}
G_{L P} \cong \frac{G_{6}}{G_{1}} \\
G_{H P} \cong 1
\end{aligned}
$$

$$
G_{B P} \cong \frac{C_{2} G_{6}}{C_{1} G_{3}}
$$

From (2) and (3), it can be seen that the parameter $\omega_{0}$ can be adjusted by controlling the resistor $R_{1}=\frac{1}{G_{1}}$ without disturbing the parameter $\frac{\omega_{0}}{Q_{0}}$. Moreover, the parameter $\frac{\omega_{0}}{Q_{0}}$ can be adjusted by controlling the capacitor $C_{1}$ without disturbing the parameter $\frac{\omega_{0}}{Q_{0}}$. Thus, the proposed circuit enjoys independent control of the parameters $\omega_{0}$ and $\frac{\omega_{0}}{Q_{0}}$.

From (2) and (3), it is easy to show that the active and passive sensitivities of the parameters $\omega_{0}$ and $Q_{0}$ are

$$
\begin{gathered}
S_{\alpha_{1}}^{\omega_{0}}=S_{\alpha_{2}}^{\omega_{0}}=S_{\alpha_{3}}^{\omega_{0}}=-S_{\beta_{1}}^{\omega_{0}}=-S_{\beta_{2}}^{\omega_{0}}+=-S_{\beta_{3}}^{\omega_{0}}=-\frac{1}{2} \\
S_{C_{2}}^{\omega_{0}}=S_{C_{4}}^{\omega_{0}}=S_{G_{6}}^{\omega_{0}}=-S_{G_{1}}^{\omega_{0}}=-S_{G_{3}}^{\omega_{0}}+=-S_{G_{5}}^{\omega_{0}}=-\frac{1}{2} \\
S_{\alpha_{1}}^{Q_{0}}=S_{\alpha_{2}}^{Q_{0}}=S_{\alpha_{3}}^{Q_{0}}=S_{\beta_{1}}^{Q_{0}}=-S_{\beta_{2}}^{Q_{0}}+=-S_{\beta_{3}}^{Q_{0}}=\frac{1}{2} \\
S_{C_{2}}^{Q_{0}}=S_{C_{4}}^{Q_{0}}=S_{G_{6}}^{Q_{0}}=S_{G_{3}}^{Q_{0}}=-S_{G_{5}}^{Q_{0}}=\frac{1}{2} \\
S_{C_{1}}^{Q_{0}}=-1, S_{C_{1}}^{\omega_{0}}=0,
\end{gathered}
$$

all of which are small.

\section{EXPERIMENTAL RESULTS}

To verify the theoretical analysis, the proposed circuit was used to realize lowpass, highpass, bandpass, notch, and allpass filters. Although there are several ways to implement the FTFNs required $[1,2,4,5,11,13]$, the experimental results were obtained using the two-current conveyor realization of 


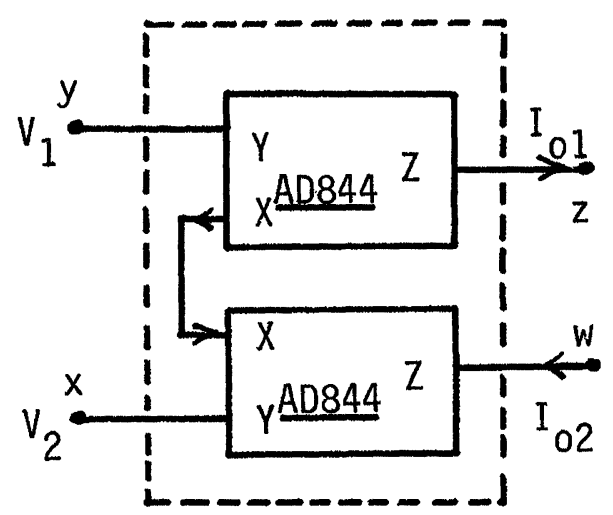

FIGURE 3 FTFN realization using two CCIIs

the FTFN proposed in [5] and shown in Fig. 3. This realization was adopted because it provides very high impedances at the $\mathrm{z}$ - and w-terminals. Thus, while the FTFNs in Fig. 1 are configured as second-generation current conveyors (CCIIs), these CCIIs have very high impedances at ports $\mathrm{x}, \mathrm{y}$, and $z$. This avoids the conversion errors or the incorrect transfer functions resulting from parasitic resistances at port $x$ of conventional CCIIs. The experimental results obtained are shown in Fig. 4, which agrees very well with the presentedtheory.

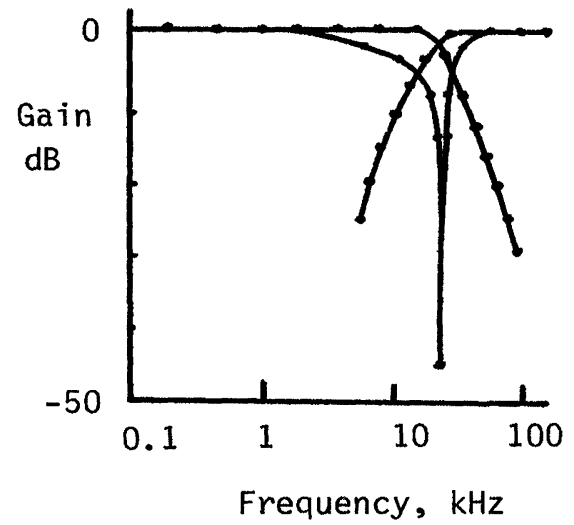

FIGURE 4 Measured and Calculated characteristics of the LPF, HPF and BPF obtained from the circuit of Fig. 1.

$\mathrm{R}_{1}=\mathrm{R}_{3}=\mathrm{R}_{5}=\mathrm{R}_{6}=5 \mathrm{~K} \Omega, \mathrm{C}_{1}=\mathrm{C}_{2}=\mathrm{C}_{4}=1.2 \mathrm{nF}$

-: Measured - : Calculated 


\section{CONCLUSION}

A universal current-mode filter has been presented. The circuit has three inputs and one output and can realize lowpass, highpass, bandpass, notch, and allpass tranfer functions without any changes in the circuit topology. The proposed filter enjoys the following advantages:

i. All the passive elements are grounded

ii. Independent tuning of the parameters $\omega_{0}$ and $\frac{\omega_{0}}{Q_{0}}$.

iii. Low active and passive sensitivities.

\section{References}

[1] E.H. Nordholt, Extending Op Amp capabilities by using a current-source power supply, IEEE Transactions on Circuits and Systems, Vol.CAS-29, 1982, pp.411-414

[2] J.H. Huijsing and J. De Korte, Monolithic nullor- A universal active network element, IEEE Journal of Solid-State Circuits, Vol.SC-12, 1977, pp.59-64

[3] M. Higashimura, Realisation of current-mode transfer function using four-terminal floating nullor, Electronics Letters, Vol.27, 1991, pp.170-171

[4] J.H. Huijsing, Operational floating amplifier, IEE Proceddings, Vol.137, Pt. G, 1990, pp.131-136

[5] R. Senani, A novel application of four-terminal floating nullors, Proceedings of the IEEE, Vol.75, 1987, pp.1544-1546

[6] R. Senani, Generation of new two-amplifier synthetic floating inductors, Electronics Letters, Vol. 23, 1987, pp.1202-1203

[7] M. Higashimura, Current-mode allpass filter using FTFN with grounded capacitor, Electronics Letters, Vol.27, 1991, pp.1182-1183

[8] S.-I. Liu, Cascadable current-mode filters using single FTFN, Electronics Letters, Vol.31,1995, pp.1965-1966

[9] S.-I. Liu and J.-L. Lee, Insensitive current/voltage-mode filters using FTFNs, Electronics Letters, Vol.32, 1996, pp.1079-1080

[10] M.T. Abuelma'atti, Cacadable current-mode filters using single FTFN, Electronics Letters, Vol. 32, 1996, pp.1457-1458

[11] R. Senani, On equivalent forms of single Op-Amp sinusoidal RC oscillators, IEEE Transactions on Circuits and Systems-I: Fundamental Theory and Applications, Vol.41, 1994, pp.617-624

[12] S.-I Liu and Y.-H. Liao, Current-mode quadrature sinusoidal oscillator using single FTFN, International Journal of Electronics, Vol. 81, 1996, pp.171-175

[13] J.K. Stevenson, Two-way circuits with inverse transmission properties, Electronics Letters, Vol. 20, 1984, pp.965-967 

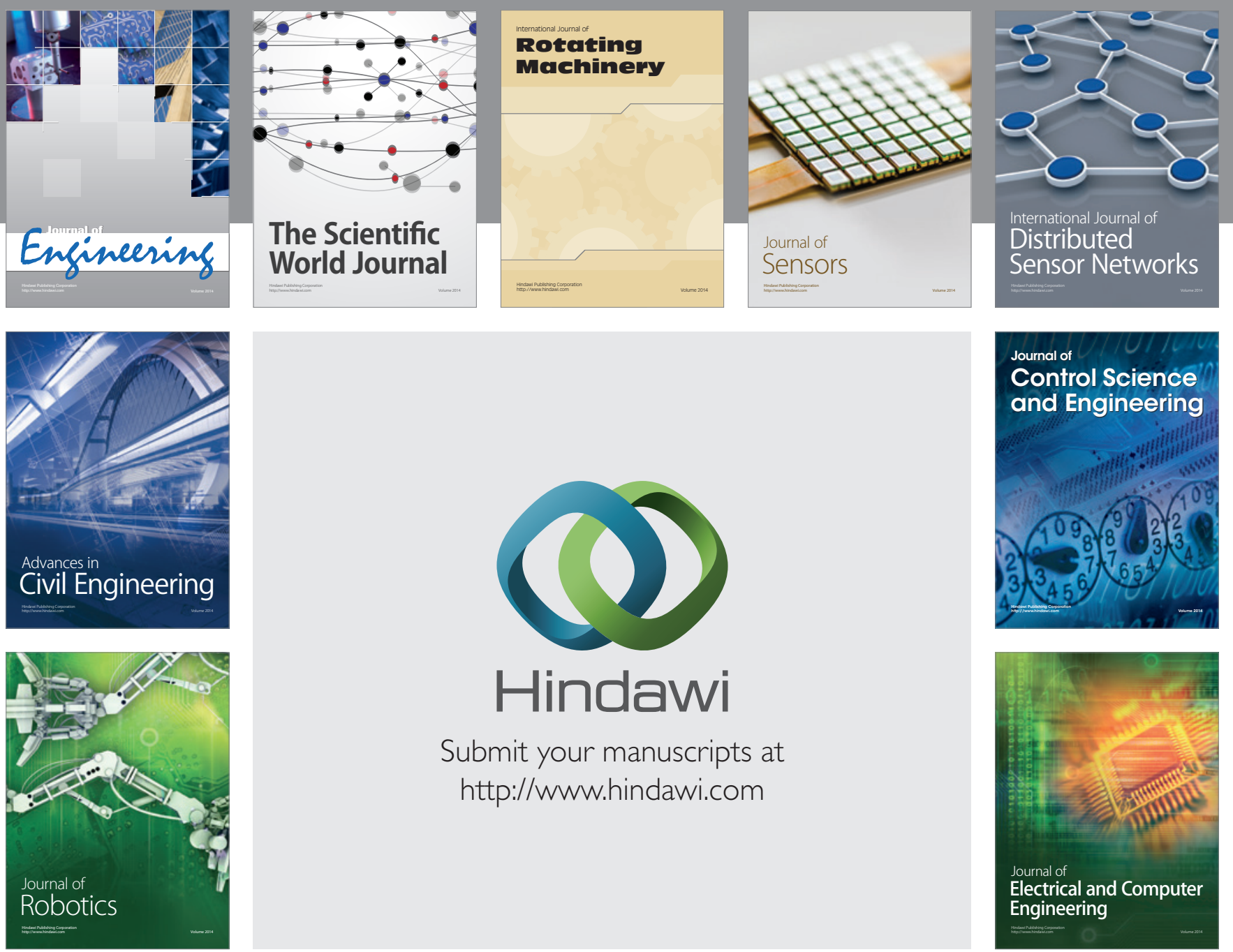

Submit your manuscripts at

http://www.hindawi.com
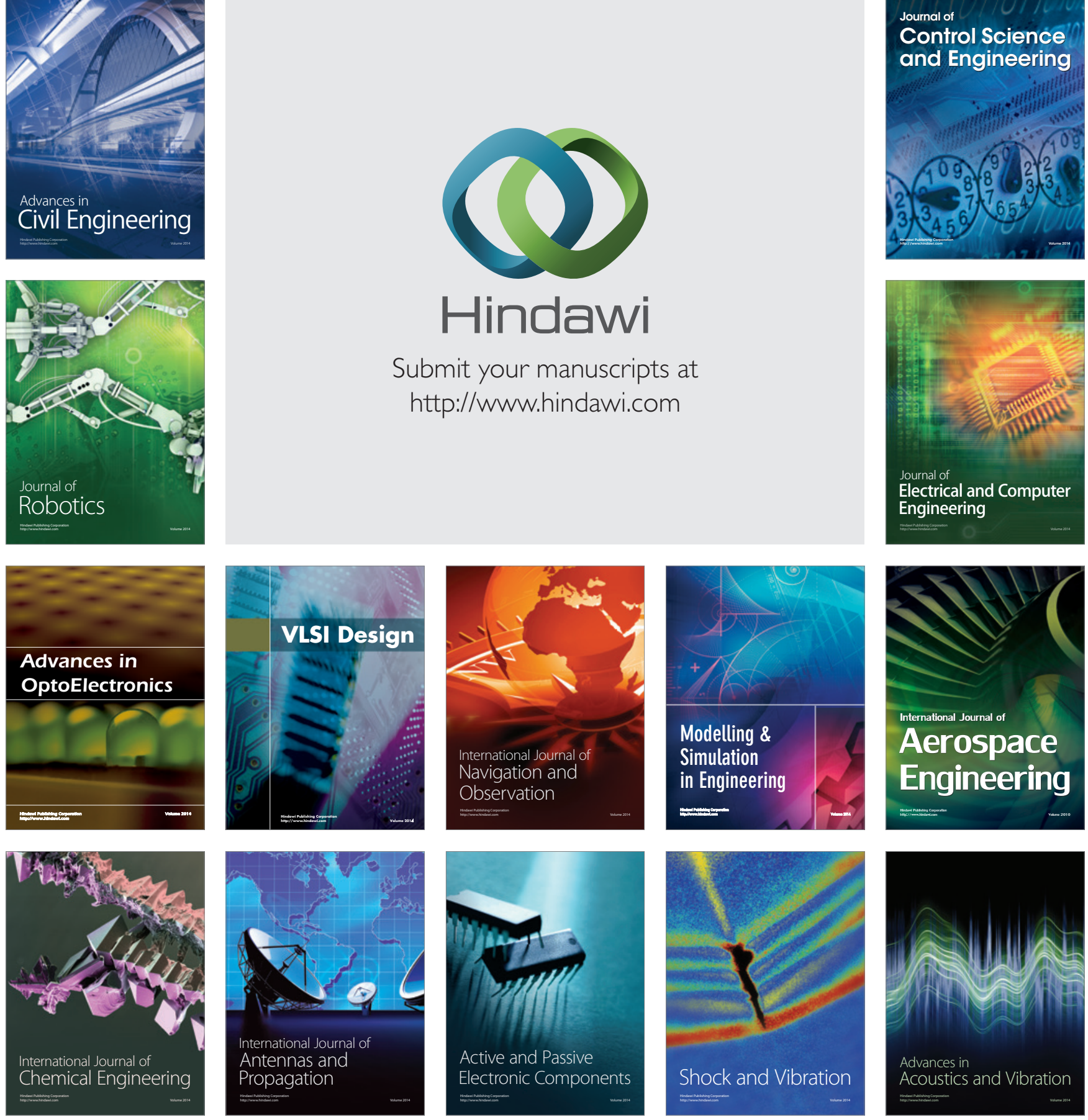